\title{
Technical and Economic Assessment of Seawater Air Conditioning in Hotels
}

\author{
Dinesh Surroop and Abba Abhishekanand
}

\begin{abstract}
Cold seawater air-conditioning is a process in which seawater from the deep ocean is pumped to a heat exchanger to process the cooling load of large buildings. The use of cold seawater air conditioning is most competitive in tropical islands, where air conditioning demands are high and the physical distance to cold seawater is at a minimum. This study was therefore initiated to assess the technical and economical aspect of using deep seawater to meet the air conditioning load for hotels located near the sea, having a cooling load of around 1000 tons $\mathrm{A} / \mathrm{C}$ which is equivalent to 3.5 GW.

Three cooling system options were chosen for study namely the Vapor compression chiller system (Option 1), Direct Seawater Air Conditioning (Option 2) and Seawater Air Conditioning using Chiller (Option 3). The conventional vapor compression system was used as a baseline to compare the other options that use cold seawater. The direct cold seawater air conditioning system consisted of a large seawater pipeline and pump to deliver cold seawater to a large heat exchanger that transfers heat directly with the building's chilled water system. The third option was similar to the second one; however, it consisted of a reversible chiller to further cool the fresh water.

The technical assessment of the three options consisted of the power consumption of each system to meet the hotel cooling load. Power consumption was found to be $3500 \mathrm{~kW}, 470 \mathrm{~kW}$ and $1870 \mathrm{~kW}$ for the three options respectively. The carbon dioxide gas emissions that would be avoided were found to be 13 ton and 7 ton per day by implementing option 2 and 3 respectively compared to option 1 . The economic assessment showed that option 2 had a payback period of 6.5 years while the investments costs on option 3 would be recovered in 4 years.
\end{abstract}

Index Terms-Air condition, cooling, sea water.

\section{INTRODUCTION}

Seawater Air Conditioning (SWAC) is an alternateenergy system that uses the cold water from the deep ocean or from deep lake to cool buildings instead of using existing type of systems. The SWAC enables a significant reduction in power consumption and it can be very cost-effective and attractive investment. It is a potential form of energy used for air conditioning.

The seawater air conditioning consists of two main loops. The first one consist of cold seawater is drawn from the ocean by centrifugal pumps and then fed in heat exchangers. The cold seawater cool, down the other medium which is water and itself gets heated up. After cooling the water, the warmed seawater is discharged to ocean. The second loop consists of a system which carries cooling water for building

Manuscript received July 12, 2013; revised September 16, 2013.

The authors are with the Department of Chemical and Environmental Engineering, Faculty of Engineering, University of Mauritius, Reduit, Mauritius (email: dsurroop@uom.ac.mu, abhi_rcpl@yahoo.com).

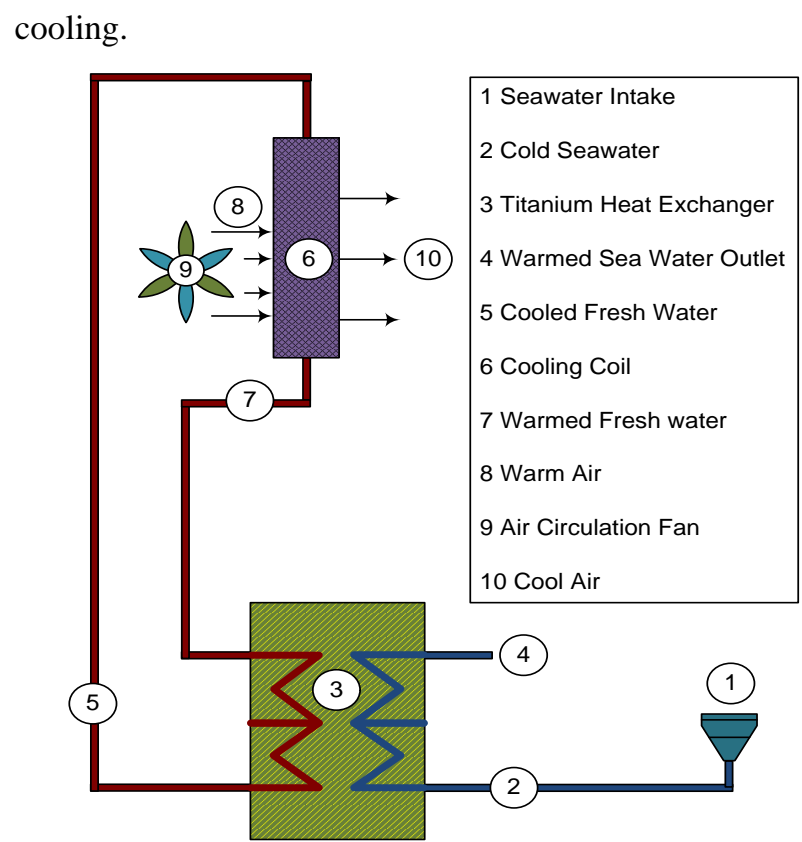

Fig. 1. Seawater air conditioning

In the heat exchanger, this water is chilled as its heat is transferred to the seawater. The chilled water is then circulated throughout the building by a pump. Cool air is delivered to each floor by an air circulation fan that moves the warm building air through a cooling coil that is part of the cooling water loop. Fig. 1 shows a typical setup of SWAC.

This study was therefore initiated to investigate the potential of energy saving by using seawater air conditioning. The goal was to reduce the amount of energy consumption by implementing less power consuming systems.

\section{OVERVIEW OF COOLING SYSTEM}

\section{A. Conventional Air Conditioner}

The most common form of meeting a large building airconditioning demand is by using a vapor compression air conditioning plant. A simplified schematic of a vaporcompression air conditioning system that is used to meet the air-conditioning load of a large hotel is shown in Fig. 2.

A compressor is used to compress and raise the pressure of a working fluid (refrigerant), in a gaseous state. This compressed refrigerant gas is then condensed in the condenser by releasing heat to the surrounding, or by using condenser water, circulated through a cooling tower $\left(\mathrm{Q}_{\text {cond }}\right)$. The condensed gas is then throttled in an expansion valve, after which the throttled liquid is evaporated in the 
evaporator. The evaporation process absorbs heat from the environment $\left(Q_{\text {evap}}\right)$, providing a cooling effect. The refrigerant gas returns to the compressor to then repeat the cycle.

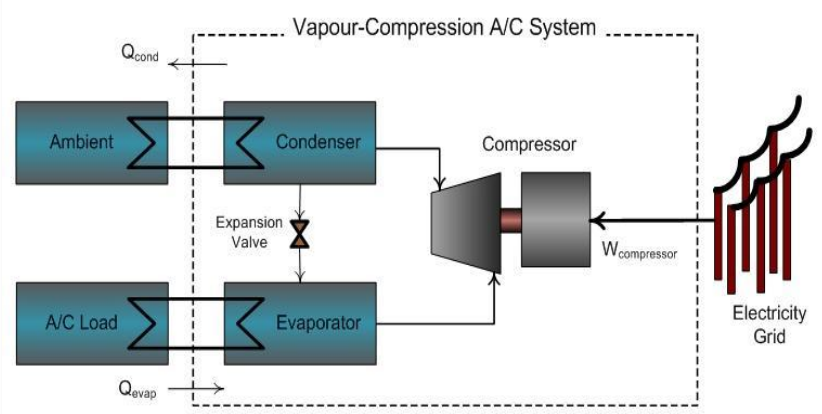

Fig. 2. Conventional air conditioner

\section{B. Direct Cold Seawater Cooling System}

The main components of a basic seawater air conditioning system are the seawater supply system, the heat exchanger or cooling station and the fresh water distribution system. These basic components can be optimized for each specific location, climate and building.

The seawater is at a much lower temperature compared to the temperature maintained in the chilled water loop. Once the seawater passes through the heat exchanger(s), it absorbed the heat of the other medium (water) in the heat exchanger whereby the temperature of the seawater is increased and it the warmed seawater is discharged to the ocean through another pipeline.

The operation of the system could be briefed as follows:

- Water is pumped from a deep cold water source

- The cooling station contain heat exchangers

- A fresh water closed loop distribution system is pumped through the heat exchangers cooling the water.

- Cooled water is pumped to buildings and used in air conditioning through fan coil units, eliminating the use of expensive compressors.

\section{Seawater Air Conditioning System Including Use of an} Auxiliary Chiller

In some cases, it is technically not possible to supply seawater at the low temperatures to achieve the minimum temperatures in the chilled water loop as the depth to achieve the required temperature might be prohibitive or the ocean depth may simply not be available. Hence it turns out to be economically not feasible. It is sometimes economically feasible to use chillers to supplement the cooling provided by the seawater exposure. The typical arrangement of this system is shown in Fig. 3.

The fresh chilled water is first cooled by seawater through a heat exchanger and then secondarily cooled with an auxiliary chiller. The auxiliary chiller is basically a refrigeration system with its condenser cooled by the returning flow of cool seawater. With the condenser kept cool, the auxiliary chiller can operate at an extremely high efficiency such that it can go as high as double that of a conventional chiller.

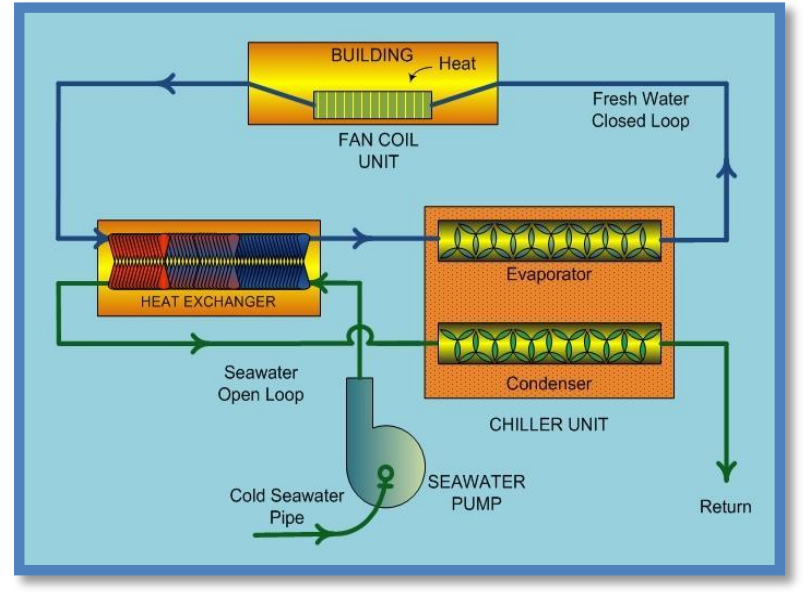

Fig. 3. Sea Water air conditioning assisted by chiller unit "Source: Adapted from makai ocean engineering [1]

\section{Methodology}

\section{A. Cooling Load}

An estimate of the cooling load of a system could be calculated by determining what the load is required to cool and dehumidify outdoor air to the desired indoor air conditions given an air-change value. It should be noted that only the sensible and latent heat was considered for the cooling load. The volumetric flow rate corresponding to the given air change could be determined by the following equation:

$$
\dot{Q}=\frac{A C H \times v}{C}
$$

where

$$
\begin{aligned}
& Q=\text { Volumetric air flow rate corresponding to } \\
& \text { given air change in } \mathrm{m}^{3} / \mathrm{s}
\end{aligned}
$$

ACH $=$ Number of air changes per hour

$v=$ Internal volume of the hotel in $\mathrm{m}^{3}$

$C=$ Time Conversion Constant

Once the volumetric flow rate was determined, the sensible and latent components of the estimated cooling load were determined independently by the following equations:

$$
\dot{q}_{s}=\frac{\dot{Q} \times C_{p} \times\left(t_{o}-t_{i}\right)}{V_{0}}
$$

where

$$
\begin{aligned}
& \dot{q}_{s}=\text { Sensible load in } \mathrm{kW} \\
& \begin{aligned}
\dot{\mathrm{Q}}= & \text { Volumetric air flow rate corresponding to given air } \\
& \text { change in } \mathrm{m}^{3} / \mathrm{s}
\end{aligned} \\
& C_{p}=\text { Specif ic heat of air in } \mathrm{kJ} / \mathrm{kg} \mathrm{K} \\
& t_{0}=\text { Outside dry bulb temperatures in } K \\
& t_{i}=\text { Inside dry bulb temperatures in } K \\
& V_{0}=\text { Specif ic volume in } \mathrm{m}^{3} / \mathrm{kg}
\end{aligned}
$$

and

$$
\dot{q}_{1}=\frac{\dot{Q} \times\left(w_{0}-w_{i}\right) \times i_{f g}}{V_{o}}
$$

where

$$
\begin{aligned}
& \dot{q}_{1}=\text { Latent load in } \mathrm{kW} \\
& \dot{Q}=\text { Volumetric air flow rate corresponding to } \\
& \quad \text { given air change in } \mathrm{m}^{3} / \mathrm{s} \\
& w_{o}=\text { Outside humidity ratios }
\end{aligned}
$$


$w_{i}=$ Inside humidity ratios

$V_{o}=$ Specific volume in $\mathrm{m}^{3} / \mathrm{kg}$

$i_{f g}=$ Latent heat of vaporization at indoor conditions in $\mathrm{kJ} / \mathrm{kg}$

From property tables and the psychrometric chart, the parameters to be used in the above equations were determined. The number of air changes per hour $(\mathrm{ACH})$ that is experienced by a building depends on the building type, construction and use. The range was found out to be from 0.5 to $2.0 \mathrm{ACH}[2]$.

When considering the design of most tropical resort hotels, an air change value of 2.0 was a reasonable assumption since no other heat gains were included. The total cooling load can then be calculated by adding the sensible load to the latent load.

where

$$
\dot{q}_{t}=\dot{q}_{s}+\dot{q}_{1}
$$

$$
\begin{aligned}
& \dot{q}_{t}=\text { Total cooling load in } k W \\
& \dot{q}_{s}=\text { Sensible load in } k W \\
& \dot{q}_{1}=\text { Latent load in } k W
\end{aligned}
$$

Having obtained the cooling load, the energy demand of each system could now be calculated.

\section{B. Power Consumption}

\section{1) Power consumption of conventional A/C system}

Knowing the air conditioning cooling load, the electricity demand of the system could be obtained. For each ton of air conditioning, a typical locally used air conditioner uses 3.5 $\mathrm{kW}$ of power.

\section{2) Power consumption of direct seawater cooling}

The use of cold seawater for air conditioning purposes would provide benefits over conventional air conditioning systems, in buildings where the distance to cold seawater is not prohibitive. In order to compare cold seawater air conditioning system to other systems, over a wide range of air conditioning demands, the electricity demand of the system should be determined over that range. The setup of a SWAC system is shown in Fig. 4.

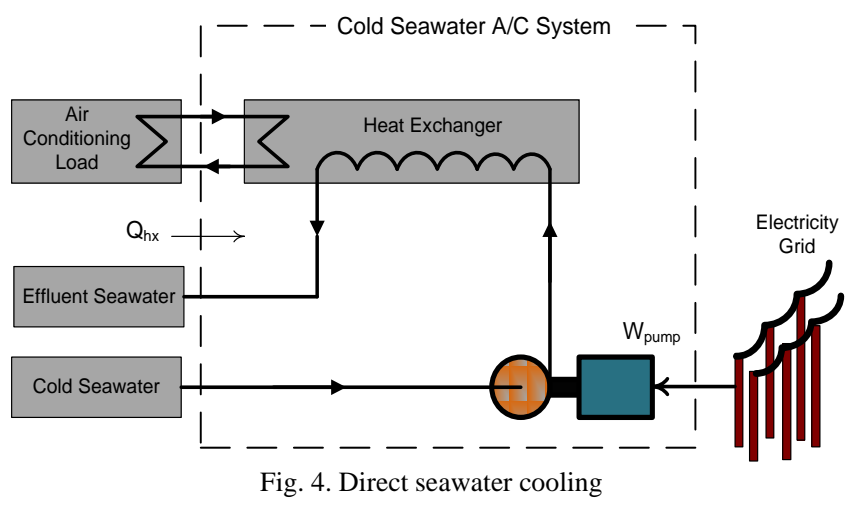

The energy demand for this system would be the amount of energy required to generate the necessary flow of seawater through the heat exchanger. The energy requirements for chilled water pumping have not been considered since they would be the same for all options. The first step in determining the energy demand for the cold seawater pump was to determine the mass flow rate of seawater required to provide the necessary cooling. Once this was determined, the parameters of the seawater delivery system could be selected. From the geometry of the seawater delivery system and the seawater flow rate, a total pressure loss or head loss could be determined. The total head loss, along with the mass flow rate provided the required pumping power that would be the power required to move a given mass flow rate of seawater through a pipedelivery system with a known head loss.

3) Seawater flow rates

The seawater flow rates were calculated using the following equation:

$$
q=\dot{m} \times C_{p} \times \Delta T
$$

where

$$
\begin{aligned}
q= & \text { Heat transfer rate (Cooling load) in } \mathrm{kW} \\
\dot{m}= & \text { Mass flow rate to the cold seawater in } \mathrm{kg} / \mathrm{s} \\
C_{p}= & \text { Specific heat capacity of the cold seawater } \\
& \text { in } \mathrm{kJ} / \mathrm{kgK} \\
\Delta T= & \text { Temperature difference between entering } \\
& \text { and exiting seawater in } K
\end{aligned}
$$

The specific heat of seawater was taken as $3.94 \mathrm{~kJ} / \mathrm{kg} \mathrm{K}$ [3]. In order to determine the required seawater mass flow rate, for a given cooling load, the following relation is used:

$$
\dot{m}=\frac{q}{C_{p} \times \Delta T}
$$

\section{4) Total head loss and seawater pumping power}

The pumping power required to move the seawater through the seawater pipeline is given by the following formula [4]:

where

$$
P=Q \times \rho \times \dot{g} \times H_{\text {total }}
$$

$P=$ Pumping power in $k W$

$\dot{Q}=$ Volumetric flow rate of seawater in $\mathrm{m}^{3} / \mathrm{s}$

$\rho=$ Density of seawater in $\mathrm{kg} / \mathrm{m}^{3}$

$g=$ Acceleration of gravity in $\mathrm{m} 2 / \mathrm{s}$

$H_{\text {total }}=$ Total pumping head in $m$

One of the major components of the total head is the suction head, which could be determined empirically by the use of the Hazen-Williams formula. The Hazen- Williams formula is given by [5]:

$$
V=1.318 \times C \times R^{0.63} \times S^{0.54}
$$

where

$$
V=\text { Velocity in } \mathrm{m} / \mathrm{s}
$$

$C=$ Hazen - Williams Roughness Coefficient

$R=$ Hydraulic Radius in $m$ (C-S Area/Wetted Perimeter)

$S=$ Slope of the energy grade line (head loss/unit length of conduit)

The pipeline was assumed to be made of polyethylene; polyethylene pipes have a Hazen-Williams Roughness Coefficient, C, of 155 [6].

Another important contribution to the total head was the entry and exit head due to the sudden acceleration of the seawater at the pipe inlet, as well as the sudden deceleration at the effluent discharge. According to Johnson (1992) [4], the following relation could determine the entry and exit losses:

$$
H_{e x}=\frac{1.5 \times\left(\frac{v}{a o}\right)^{2}}{2 g}
$$


where

$$
V=\text { Velocity in } \mathrm{m} / \mathrm{s}
$$

$a o=$ Cross - sectional Area in $m 2$

$g=$ Acceleration due to gravity in $\mathrm{m} / \mathrm{s}^{2}$

The head loss through the heat exchangers and other various valves, turns and fittings were assumed to be approximately $0.3048 \mathrm{~m}$. The height above sea level that the heat exchangers are located is estimated at $1.524 \mathrm{~m}$ since the hotels are so close to shore. With these assumptions, the total head for each seawater flow rate of interest could be determined.

From these total head values, the total pumping power could be determined. Then by assuming pump efficiency and corresponding electric motor efficiency, the electrical demand for a direct seawater air conditioning system could be determined.

\section{5) Power consumption of SWAC system using chiller}

The third option of air conditioning system worked approximately the same as the second option but differed in the way that instead of installing pipes over long distances deep in the sea, seawater could be pumped from a depth of $20 \mathrm{~m}$ below the ground level of the hotel situated in the coastal region. It should be highlighted that at a depth of 20 $\mathrm{m}$, seawater is obtained on coastal areas only.

The equations used for the calculation of the seawater flow rate, head loss and pumping power for this system was similar to the above calculations. Only few parameters were different. In addition, the power consumed by the chiller unit was estimated at $130 \mathrm{~kW}$ (value obtained from manufacturer brochure).

\section{Greenhouse Gas Emissions Avoided}

The amount of energy saved was calculated and its corresponding greenhouse gas emission was calculated. The amount of power saved in MWh was calculated and the amount of carbon dioxide was determined.

\section{RESUlts}

\section{A. Cooling Load}

Table I shows the room size and corresponding hotel volume used to determine the cooling load.

The number of rooms assumed in this study was the average number of rooms in 4 star hotels in Mauritius. The other rooms represented the other hotel spaces like restaurants, spa, and gymnasium. The determination of this value was useful in further calculating the cooling load required. A cooling load of approximately 1000 tons was estimated by using the air change method.

TABLE I: ESTIMATION OF VOLUME OF HOTEL

\begin{tabular}{ccccc}
\hline Size of Room $/ \mathrm{m}$ & Volume of one Room $/ \mathrm{m}^{3}$ & No. of rooms & Volume of Rooms $/ \mathrm{m}^{3}$ & Volume of other rooms $/ \mathrm{m}^{3}$ \\
\hline $7.6 \times 7.6 \times 4.9$ & 283 & 300 & 84,910 & 618,440 \\
\hline
\end{tabular}

TABLE II: COOLING LOAD ESTIMATION FOR A ROOMS HOTELS WITH ACH $=2.0$.

\begin{tabular}{cccc}
\hline Air Flow Rate & Sensible Load & Latent Load & Tons A/C \\
\hline$\dot{Q}$ & $\dot{q}_{s}$ & $\dot{q}_{1}$ & $\dot{q}_{t}$ \\
$81.6 \mathrm{~m}^{3} / \mathrm{s}$ & $960 \mathrm{~kW}$ & $2,560 \mathrm{~kW}$ & 12000 \\
\hline
\end{tabular}

\section{B. Seawater Flow Rate}

The seawater flow rates were calculated using the basic specific heat capacity equation. The two seawater air conditioning systems shared approximately the same seawater flow rate. However, the pumping power would differ significantly since the head from which the seawater was being pumped differed significantly. Both seawater air conditioning systems have been considered according to the same cooling load (1000 tons $\mathrm{A} / \mathrm{C}$ ). The difference of 10 $\mathrm{kg} / \mathrm{s}$ accounts for the difference in temperatures around the heat exchanger of each system.

\begin{tabular}{cc} 
TABLE III: Flow RATE OF SEAWATER \\
\hline Seawater Flow rate in kg/s \\
Option 2- Direct SWAC & Option 3- SWAC using Chiller \\
160 & 150 \\
\hline
\end{tabular}

\section{Power Consumption}

Table IV shows the different amount of power consumed by each system for the same cooling load.

\section{1) Comparison between option 2 and option 3}

The main difference between these two seawater air conditioning systems was that one made use of a reversible chiller to cool the freshwater since its seawater was drawn from a depth of only $20 \mathrm{~m}$. A reversible chiller was required in order to further lower the temperature of the freshwater which was pre-cooled by the seawater. Since the seawater was drawn from a depth of $20 \mathrm{~m}$ below ground level, its temperature was higher than that of the seawater drawn from $800 \mathrm{~m}$ far from the coast.

TABLE IV: POWER CONSUMPTION

\begin{tabular}{cccc}
\hline Cooling Load & 1000 tons A/C & 1000 tons & 1000 tons A/C \\
& A/C & \\
\hline Option & Conventional & SWAC & SWAC using \\
& & & Chiller \\
Power & $3500 \mathrm{~kW}$ & $416.8 \mathrm{~kW}$ & $1866.8 \mathrm{~kW}$ \\
Consumption & & & \\
\hline
\end{tabular}

2) Comparison between conventional system and SWAC systems

The SWAC systems consumed lower amount of electricity compared to the conventional system. This was because SWAC systems make use of pumps, chiller and fan coil units as power consumers. These pumps and fan coil units consumed little amount of power compared to conventional systems. The heat exchanger which would 
cause a considerable temperature change of the freshwater would use no power at all. The power saved by implementing seawater air conditioning instead of conventional systems is shown below.

TABLE V: POWER SAVINGS FOR COOLING LOAD OF 1000 TONS A/C Option Conventional SWAC $\quad$ SWAC using

Chiller

\begin{tabular}{cccc}
\hline Power Consumption & $3500 \mathrm{~kW}$ & $416.8 \mathrm{~kW}$ & $1866.8 \mathrm{~kW}$ \\
$(\mathrm{~kW})$ & & & \\
Power Saved $(\mathrm{kW})$ & - & 3083.2 & 1633.2 \\
Percentage saved & - & $88 \%$ & $47 \%$ \\
\hline
\end{tabular}

Similar projects have shown an energy savings of greater than $75 \%$ at the Honolulu Seawater Air Conditioning and $90 \%$ according to Aloha (2010). The Figs. of $75 \%$ and $90 \%$ apply for Option 2 (Direct Seawater Air Conditioning). As for Option 3 (Seawater Air Conditioning by use of chiller), a saving percentage of 60 to $70 \%$ has been obtained from Hypertek Hotel (Grand Bay, Mauritius). It is the only hotel which has this system installed in Mauritius.

\begin{tabular}{ccc} 
& \multicolumn{2}{c}{ TABLE VI: PowER SAVINGS COMPARISON } \\
\hline Option & $\begin{array}{c}\text { \% Power Saving } \\
\text { (Literature) }\end{array}$ & $\begin{array}{c}\text { \% Power Saving } \\
\text { (Calculated) }\end{array}$ \\
\hline $\begin{array}{c}\text { SWAC } \\
\text { SWAC using } \\
\text { Chiller }\end{array}$ & 75 to 90 & 88 \\
& 60 to 70 & 47 \\
\hline
\end{tabular}

\section{3) Considering option 2 (direct seawater air conditioning)}

The power saving percentage for Option 2 is in line with what has been stipulated in literature. This power saving value depended on several factors; even the hotel room size affects this value. The calculated Fig. falls on the higher bounds of the range. The second option results in a higher power saving due to its low pumping power.

\section{4) Considering option 3 (seawater air conditioning using chiller)}

In this case, a value of $47 \%$ was obtained. Several factors may have resulted in this value. Some of these are listed below:

1) The pumping power may have been overestimated a bit due to the high head value. This means that instead of extracting the water from a depth of $20 \mathrm{~m}, 15 \mathrm{~m}$ could have been enough. This will then decrease the head which in turn decreases the pumping power and total power consumption.

2) The operating hours of the system will depend on the amount of people there is in the hotel. The operating hours is a major parameter in determining the power consumption. For this study, the maximum number of operating hours was taken into account (2500 hours per year). Some people set their fan coil unit to minimum temperature output; in this case, when the room is cooled to a much lower temperature, they switch it off and in this way, the operating hour is decreased.

3) The chiller tank which stores the cooled water prior to circulation to fan coil units can retain the water at its lowest temperature for at least 2 days (Hypertek Hotel, Grand Bay). This means that the pump and chiller could be switched off for at least 1 day. The only power consumed will then be by the fan coil units. This can result in a higher energy saving (close to literature value of 75 to $90 \%$ ).

4) The cooling load used for the study can differ from that of the literature value. The other heads (fittings head and entry/exit head) may also affect the energy saving percentage. Also, the efficiency of the pump plays an important role in the final value.

\section{Greenhouse Gas (GHG)}

The amount of carbon dioxide avoided was calculated by using an equivalency factor of 1.1 ton $\mathrm{CO} 2$ per MWh [7]. The operating hours for the system were estimated to be 10 hours per day.

\begin{tabular}{ccc}
\multicolumn{3}{c}{ TABLE VII: CARBON DIOXIDE REDUCED } \\
\hline Option & $\begin{array}{c}\text { Power Saved } \\
(\mathrm{MWh})\end{array}$ & $\begin{array}{c}\text { Carbon Dioxide saved } \\
\text { (ton) }\end{array}$ \\
\hline SWAC (Option 1) & 30.8 & 33.9 \\
SWAC using Chiller & 16.3 & 18.0 \\
$($ Option2) & & \\
\hline
\end{tabular}

\section{E. Economic Feasibility}

\section{1) Capital investment}

One of the most important aspects in implementing seawater air conditioning is the economic factor. An economic assessment has been conducted on the two types of seawater air conditioning system and the results are displayed below.

Fig. 5 showed the fixed capital investment required to implement each system (for a cooling load of 1000 tons A/C). Option 2 (Direct Seawater Air Conditioning) showed a very high investment cost of approximately 245 million rupees while that of Option 3 (Seawater Air Conditioning using Chiller) showed a considerable lower investment cost. No doubt, the conventional system has the lowest investment cost.

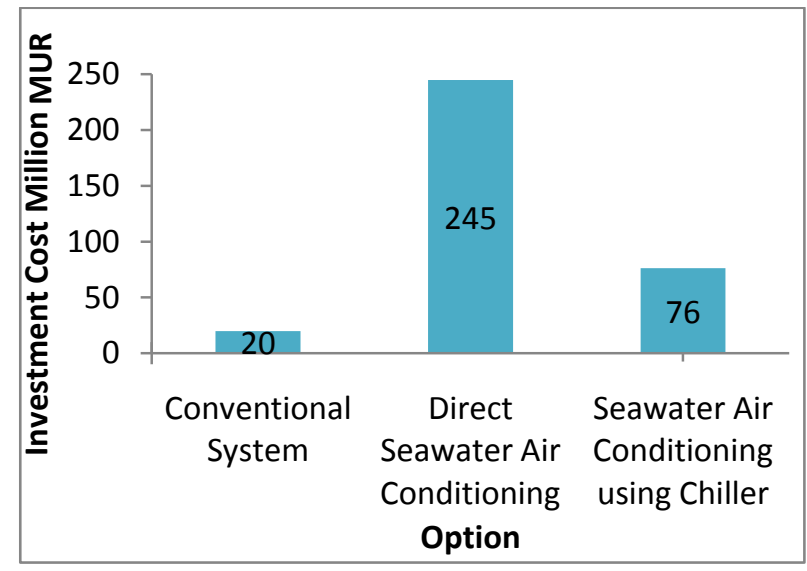

Fig. 5. Investment of each option

\section{2) Payback period}

The payback period has been calculated using the basic 
investment over savings equation. The savings were in terms of electricity that would be purchased. Due to its high investment cost, Option 2 had a higher payback period than that of Option 3. While considering a choice between Option 2 and 3, the payback period and investment cost posed as a main parameter. The disadvantages of Option 2 (Direct Seawater Air Conditioning) were that it would be almost impossible to implement it in buildings located far from the coast; moreover, it had a very high investment cost. Bearing in mind the $800 \mathrm{~m}$ pipe extension over the sea, maintenance would be costly if ever there would be a leakage. On the overall, the payback period of Option 3 deemed to be better. On the general case, Option 3 would prove to be the best system though it has a lower power saving than Option 2. But the high investment cost and installation issue of Option 2 poses as a problem in its implementation.

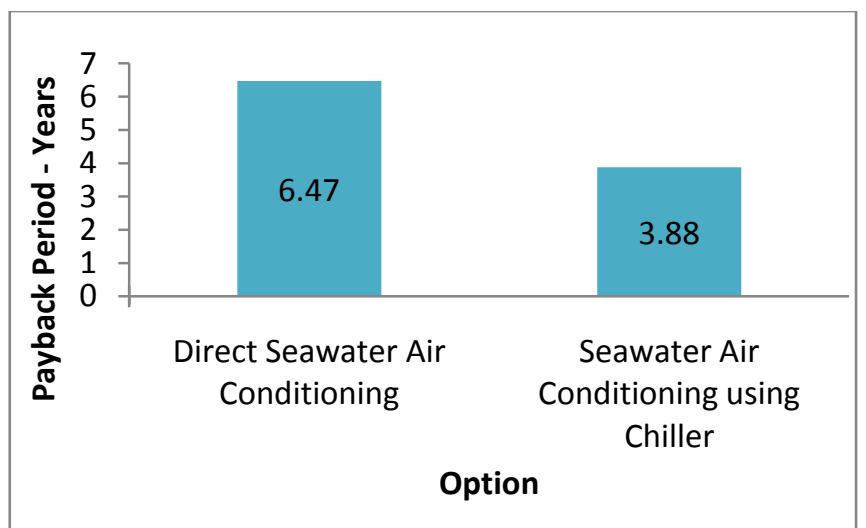

Fig. 6. Payback period

\section{CONCLUSION}

Seawater Air Conditioning is certainly regarded as one of the best emerging technologies to cover up conventional air conditioning systems and minimize fossil fuels consumption. This study has shown that seawater can be pumped to supply air conditioning for specific cooling loads. It could be deduced that seawater flow rate is proportional to cooling load; for a cooling load of 1000 tons A/C, a seawater flow rate of around $150 \mathrm{~kg} / \mathrm{s}$ was obtained. Temperature in the range 17 to $21{ }^{\circ} \mathrm{C}$ could be obtained from seawater air conditioning.

As far as power consumption is concerned, direct seawater air conditioning system (Option 2) would use around $400 \mathrm{~kW}$ and the seawater air conditioning using chiller system (Option 3) would use around $1800 \mathrm{~kW}$ while on the other hand the conventional system would use 3500
$\mathrm{kW}$ for the same cooling load. In other words, it could be concluded that Option 2 had a power saving of $88 \%$ while Option 3 around $47 \%$ compared to conventional systems. Bearing in mind the aspect of environment, it has been deduced the amount of carbon dioxide emissions avoided per day for Option 2 and 3 respectively were deduced to be 33.9 and 18 tons.

Seawater air conditioning is more expensive than conventional system. Option 2 would require an investment cost of around Rs 245 million and Option 3 would require an investment cost of around 76 million MUR while the conventional system had an investment cost of only 20 million MUR comparatively. However, Option 2 proved to have a higher power saving than Option 3. The payback periods were found to be 6.47 and 3.88 years for Option 2 and 3 respectively. Seawater air conditioning helps in reducing power consumption and greenhouse gas emissions. Option 2 could be installed only in building located on the beach while Option 3 could be implemented either on the beach or near the coast as far as seawater is obtained underground.

\section{REFERENCES}

[1] Makai Ocean Engineering. (2010). Cold Seawater Air Conditioning [online]. Available: http://www.makai.com/p-swac.htm

[2] F. C. McQuistone and J. D. Parker, Heating, Ventilating, and Air Conditioning - Analysis and Design, New York: WILEY J. \& Sons. 1994.

[3] J. A. Schetz and E. F. Allen, Fundamentals of Fluid Mechanics, John Wiley and Sons, 1999.

[4] F. A. Jonhson, "Closed cycle ocean thermal energy conversion," in: R. J. Seymour, ed., Ocean Energy Recovery - the State of the Art, New York: ASCE, Chapter 5, 1992.

[5] V. R. Giles, J. B. Evett, and C. L. Liu, Schaum's Outline of Theory and Problems of Fluid Mechanics and Hydraulics, $3^{\text {rd }}$ ed. New York: McGraw-Hill, 1994.

[6] Chevron Chemical Co., Industrial Piping System, LLC: Plexco, B., no. 301, 1999.

[7] S. D. Bagha, Quantifying Greenhouse Gases from the Production of Energy in Mauritius, University of Mauritius, 2009.

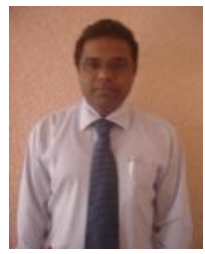

Dinesh Surroop is a senior lecture at the Department of Chemical and Environmental Engineering, Faculty of Engineering, University of Mauritius in Mauritius. His field of expertise is Waste Management, Energy Management and Alternatives Energy Recovery.

Abhishekanand Abba is a graduate student in Chemical and Renewable Energy at the department of Chemical and Environmental Engineering, Faculty of Engineering, University of Mauritius in Mauritius. 